\title{
Temperature action in analysis of thermal stressed state of massive concrete and reinforced concrete structures
}

\author{
Aleksandra Makeeva ${ }^{1 *}$, Aleksandra Amelina ${ }^{1}$, Kirill Semenov ${ }^{1}$, and Yuriy Barabanshchikov ${ }^{1}$ \\ ${ }^{1}$ Peter the Great St. Petersburg Polytechnic University, 195251 Polytechnic street 29, Russia
}

\begin{abstract}
The work is dedicated to research of the thermal stresses state of massive concrete and reinforced concrete structures in construction period. The article examines the results of the analysis of the thermal stress state, which occurs in massive concrete ground slab with thickness of $1 \mathrm{~m}$. The study was conducted with using analytical models, which include the factor of diurnal temperature range in comparison with simplified methods. Authors established that solving the problem of thermal stressed state of the massive foundation slabs in the building period without taking into account the influence temperature changing during the month might not cause to significant deviation of the real diagram of the thermal stresses and elongation deformations in the structures body: error is less than $0.5 \%$.
\end{abstract}

\section{Introduction}

In practice, calculation of thermal fields is often based on the heat equation solution as well as thermal stresses definition, linked with calculation of cracking resistance massive of concrete in construction period [1-2]. Nonstationary and non-uniform temperature fields [3-7] appear in the concrete because of cement setting [8-9] and heat exchange with the environment, consequently leading to the formation of thermal stresses [10-14]. Uneven temperature fields are the cause of tensile stresses on the surface of the foundation, which are capable of generating dangerous crack growth [15-19]. The following provisions determine the relevance and necessity of analyzing the thermally stressed state and the calculation of thermal crack resistance:

- Construction of buildings and structures requiring large-sized foundations [20];

- Construction of buildings and structures with a high level of responsibility, the durability and performance of which may suffer because of even small deformations [21].

Basic data for describing and calculating the distribution of heat in a real structure consist of the following seven parameters: geometric shape and size of the structure; thermal performance of the material; the law of heat propagation inside the structure; initial conditions (block temperature at the time of the beginning of the calculation of the process of heat release); ambient temperature; conditions of heat exchange on the surface; cement exotherm [20].

For an accurate description of the thermally stressed state of the structure, it is necessary that the seven parameters listed above be modeled with maximum confidence. Many works are devoted to the improvement of the methodology and the approximation of the computational model to real conditions [3-5.9-10.20-22]. So N.A. Malinin [3] proposed a type of concrete relaxation function, which is used to record creep; I.D. Zaporozhets [9] described the process of heat dissipation of concrete by the equation, which is used when calculating the temperature change of hardening; A.V. Chekalkin [20] solved the problem of determining the thermally stressed state and the crack resistance of the foundation of a turbine unit using MCS, etc. Most authors agree that not taking into account one factor or another leads to significant errors in the calculations [1, 2, 8, 10, 13, 14, 20-21].

Earlier, in studies of the distribution of temperature fields and a thermally stressed state, some constant average daily ambient air temperature was set [1, 2, 10, 11, 20-22]. However, there is some daily/monthly rate [23-25]. The change in ambient temperature is one of the most significant factors for a large number of processes. Accounting for the effect of temperature is quite complicated, because temperature change is a complex dynamic process containing both deterministic and random components [24, 26].

The modeling of the change in ambient temperature over a period (day, year, and month) and the assessment of the influence of this fluctuation is the work of both domestic and foreign authors. Temperature fluctuations affect the state of people, engineering systems, building materials and structures [27-28], etc. For example, in article [27] based on the findings obtained, it was possible for the first time to make direct statements about the deformation conditions occurring in an asphalt base layer because of temperature.

Most models are based on long-term meteorological observations with a daily resolution [29-30]. In [29], it was shown that the daily amplitude of temperature fluctuations of the PP is the greatest in the summer season in all the considered climatic zones. And in article [30] a model is used, for a given period of time the annual variation of the

\footnotetext{
* Corresponding author: nicealexa@mail.ru
} 
average daily air temperature of which is characterized by three parameters - the average temperature $\mathrm{T}_{0}$, as well as the amplitude of the sinusoidal function $\mathrm{A}$ and the point of its maximum $\mathrm{t}_{0}$.

Structural calculation methods involve usage of structural models made with certain simplifications that greatly facilitate the calculation. Calculation with a wrong structural model cannot be valid qualitative. For the foregoing reasons, the vital task is to estimate diurnal temperature range in structure model for the construction period.

The purpose of article is an assessment of the influence of ambient temperature fluctuations in the calculations of thermal crack resistance of massive concrete and reinforced concrete structures during the construction period and the rationale for the need for such an account.

Therefore, the purposes of current research work are:

1. To propose the calculation optimization algorithm, which should consider the diurnal temperature range;

2. To estimate the damage state by calculation methods that involve usage of structural models made with certain simplifications.

For achieving these purposes, following problems have to be solved:

1. Investigate the change in ambient air temperature during the month and obtain dependencies that could be implemented in the calculations of the thermal stress state;

2. To obtain, using the program on the example of the initial data, new results of the calculation of the thermally stressed state and to compare with the calculations obtained by the old method.

\section{Methods and Materials}

This paper demonstrates calculation of stressed state with the help of TERM software developed by the Institute of Civil Engineering at the Peter the Great St. Petersburg Polytechnic University [12, 31-33]. This software calculates nonstationary fields of temperature and thermal stresses. An essential feature of the TERM software is the consideration of temperature influence on thermophysical and stress-related concrete characteristics.

Considering horizontal mats sizes significantly exceed their height, we can study a one-dimensional structural model for the mat central part with the reasonable degree of accuracy. In this model, stress and temperature are functions of the vertical coordinate space [10].

1. The article examines the results of the analysis of the thermal stress state in construction period, which occurs in massive concrete ground slab height (thickness) $1.0 \mathrm{~m}$. Slab is laid as one block.

2. Thermal and physical characteristics of the concrete $\mathrm{B} 35$ : thermal conductivity $=2.67 \mathrm{~W} / \mathrm{m} \cdot{ }^{0} \mathrm{C}$, thermal capacity $\mathrm{c}=1.0 \mathrm{~kJ} / \mathrm{kg} \cdot{ }^{0} \mathrm{C}$;

3. Concrete mix temperature: $20^{\circ} \mathrm{C}$;

4. Ambient temperature (temperature of ambient air): constant or variable during month;

5. According to N.A. Malinin, the instantaneous elastic deformation modulus of concrete follows the equation [3]:

$$
E(t)=E_{\max }\left(1-e^{\alpha t^{\gamma}}\right)
$$

where $\mathrm{E}_{\max }=34500 \mathrm{MPa}$ is the limit value of the concrete deformation. Functional dependency parameters are $\alpha=(-0.37), \gamma=0.72$, and $t$ stands for the current time;

6. Conditions of heat transfer on the surface: third type boundary conditions. Heat transfer according to the Newton's law:

$$
\frac{\partial \tau}{\partial z}=\frac{\beta}{\lambda}\left(T_{s e}-T_{\text {surf }}\right)
$$

7. The heat dissipation process follows the I.D. Zaporozhets equation [9]:

$$
Q(\tau)=Q_{\max }\left[1-\left(1+A_{\tau} \tau\right)^{-\frac{1}{m-1}}\right]
$$

As initial data (thermophysical characteristics of concrete, cement heat radiation) the results or research, obtained in laboratory "Polytech-SKiM-Test" in CUBS department by Professor Barabanschikov Y.G. were accepted.

The following technological specifications of concrete pouring were taken into account: inside the heat enclosure, the concrete mix is poured as a single $1.0 \mathrm{~m}$ high block with the concrete mix temperature is $20^{\circ} \mathrm{C}$ and air temperature is varied. After concreting the surface is covered with insulation, which thickness is determined by the cracking prevention condition.

In order to estimate the cracking resistance of the concrete slab, we would use the deformation criterion suggested by P.I. Vasiliev [34].

\section{Results}

\subsection{Ambient temperature}

The daily variation of the ambient temperature was determined depending on the type of the climatic zone and the selected date according to tables of statistical data. For winter, the amplitude of daily fluctuations will be minimal, and for summer - maximum [23-29]. However, the winter period is the most dangerous from the technological point of view, since the temperature difference "ambient air-concrete mix" is maximum. For comparison, consider the air temperature of the coldest and warmest months of St. Petersburg (January and July, respectively) (Table 1, Table 2). 
Table 1. Maximum, minimum and average temperatures in January for 2014-2018 in the city of St. Petersburg [35, 36].

\begin{tabular}{|c|c|c|c|c|c|c|c|c|c|c|c|c|c|c|c|c|c|c|}
\hline \multirow{2}{*}{$\begin{array}{c}\text { Day } \\
/ \\
\text { year }\end{array}$} & \multicolumn{5}{|c|}{ Maximum temperature, ${ }^{0} \mathrm{C}$} & \multicolumn{5}{|c|}{ Minimum temperature, ${ }^{0} \mathrm{C}$} & \multicolumn{5}{|c|}{ Average temperature, ${ }^{0} \mathrm{C}$} & \multicolumn{3}{|c|}{ Average, ${ }^{\circ} \mathrm{C}$} \\
\hline & 14 & 15 & 16 & 17 & 18 & 14 & 15 & 16 & 17 & 18 & 14 & 15 & 16 & 17 & 18 & $\mathrm{~T}_{\max }$ & $\mathrm{T}_{\min }$ & $\mathrm{T}_{\mathrm{av}}$ \\
\hline 1 & 8 & 3 & -7.2 & 4.5 & 1.3 & -2 & 0.5 & -18 & -0.3 & -0.6 & 0.5 & 2.2 & -13.7 & 1.2 & 0.5 & 0.76 & -4.08 & -1.86 \\
\hline 2 & -1 & 4 & -9 & 0.4 & 4.7 & -3 & 1.7 & -18 & -4.4 & 0.8 & -2.3 & 2.7 & -14.4 & -2.1 & 3.6 & 0.18 & 4.58 & -2.5 \\
\hline 3 & 0 & 3.1 & -8 & -4.4 & 3.6 & -2 & 0 & -16 & -11.3 & 1.3 & -1.2 & 1.2 & -11.6 & -7.8 & 2.2 & 1.14 & -5.6 & -3.44 \\
\hline 4 & 1.7 & .2 & -10 & -11.3 & 3.1 & -0.6 & -8 & -20 & -15.8 & 1 & 1 & -3.9 & -15 & -14.5 & 2.2 & 3.34 & -8.68 & -6.04 \\
\hline 5 & 4 & -7 & -17 & -15.8 & 4.4 & 1 & -10 & -25 & -19.6 & 3 & 2.9 & -8.3 & -19.4 & -18.1 & 3.5 & 6.28 & -10.12 & -7.88 \\
\hline 6 & 2.5 & -9 & -18.3 & -17.5 & 3.3 & 0 & -13 & -27 & -19.7 & 1.8 & 0.7 & -10.9 & -24.4 & -18.6 & 2.4 & -7.8 & 11.58 & -10.16 \\
\hline 7 & 4 & -7.5 & $\mid-20.3$ & -15.7 & 1.9 & 1 & 13.5 & -27 & -20.6 & -3.1 & 2.2 & -9.6 & -24.7 & -18.4 & -1 & 7.52 & -12.64 & -10.3 \\
\hline 8 & 6 & -3 & $\mid-16.8$ & -4.8 & -0.1 & 0.2 & -11 & -27 & -15.7 & -3.5 & 4 & -7.7 & -23.7 & -9.4 & -1.7 & -3.74 & -11.4 & -7.7 \\
\hline 9 & 6 & 1.2 & -17.2 & 0.9 & 0.3 & 3 & -6 & -26 & -4.8 & -5.4 & 4.6 & 0.1 & -21.4 & -1.1 & -2.7 & -1.76 & -7.84 & -4.1 \\
\hline 10 & 4 & 0 & -14.6 & 2 & 0.9 & -2 & -2 & -22 & -0.3 & -1.9 & 1.9 & -1.1 & -20.1 & 0.8 & -0.2 & -1.54 & -5.64 & -3.74 \\
\hline 11 & -2 & -0.7 & -12 & 1.5 & -1.2 & -6 & -2.1 & -21 & -6.6 & -3 & -4.7 & -1.4 & -16.1 & -4.3 & -1.9 & -2.88 & -7.74 & -5.68 \\
\hline 12 & -5 & -1 & -8.5 & -2.3 & -1.8 & -8 & -11 & -12.9 & -5.6 & -5 & -5.7 & $\begin{array}{l}-7.1 \\
\end{array}$ & -9.6 & -3.7 & -3.2 & -3.72 & -8.5 & -5.86 \\
\hline 13 & -7 & 2.3 & -8.7 & 1.5 & -4.1 & -10 & -11.2 & -13 & -5.6 & -7.8 & -7.9 & -2.2 & \begin{tabular}{|l|}
-10.4 \\
\end{tabular} & -2.2 & -5.7 & -3.2 & -9.52 & -5.68 \\
\hline 14 & -8 & 3 & 1.7 & 1.3 & -3.2 & -11.8 & -3 & -23 & -1.3 & -5.8 & -9 & 0.9 & -16.7 & 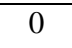 & -4.6 & 3.72 & -8.98 & -5.88 \\
\hline 15 & -7.2 & 2.1 & 1.9 & 0.3 & -4.4 & -14 & -1 & -23 & -2.3 & -0.1 & & 1.1 & & -0.9 & -7.4 & 4.22 & 9.68 & -7.1 \\
\hline 16 & -7 & 3.3 & -13.1 & -1.7 & -7.6 & 0.3 & -1 & -21.7 & -4.4 & -10.7 & -9.2 & 0.9 & -17.7 & -2.8 & -9.1 & 5.22 & -9.62 & -7.58 \\
\hline 17 & & 3.4 & -9 & -3 & -5 & 16 & 1 & -21 & -4.8 & -9.1 & -12.1 & 2.2 & -15.4 & 4 & \begin{tabular}{|l|}
-7.1 \\
\end{tabular} & 4.54 & -9.98 & -7.28 \\
\hline 18 & -10.5 & 3 & -12 & 0.3 & -4.4 & -15 & 1 & -23.1 & -4.3 & -6.5 & -13.2 & 1.7 & \begin{tabular}{|l|}
-16.7 \\
\end{tabular} & -1.9 & -5.5 & -4.72 & -9.58 & -7.12 \\
\hline 19 & -8.9 & 1.3 & -2.4 & 2.1 & -1.7 & -17 & -6 & -14.5 & 0 & -4.8 & -13.9 & -0.8 & -5.8 & 0.9 & -2.7 & 1.92 & -8.46 & -4.46 \\
\hline 20 & -9.7 & -4.9 & -6.1 & 2 & -3 & -16.3 & -15 & -10.1 & -2.3 & -6.4 & -12.1 & -10.3 & -8.3 & -0.5 & -4.9 & -4.34 & -10.02 & -7.22 \\
\hline 21 & -7.4 & -8.4 & -9 & -1.2 & -6.4 & $\mid-11.1$ & -18 & -15 & -5.7 & -11.2 & -9 & -15 & \begin{tabular}{|l|}
-10.7 \\
\end{tabular} & -3.5 & -8.9 & -6.48 & -12.2 & -9.42 \\
\hline 22 & -9.5 & -9 & -14.6 & 1.4 & -8.9 & -20 & -17 & -23.5 & -6 & -14.7 & -12.6 & -12.5 & -18.3 & -1.4 & -11.1 & -8.12 & -16.24 & -11.18 \\
\hline 23 & -14 & -2.2 & 0.9 & 0.8 & -9.5 & -22 & -10 & -24 & 0.2 & -14.7 & -17.6 & -5.2 & -18.2 & 0.6 & -12.7 & -7.16 & -14.1 & -10.62 \\
\hline 24 & -10.9 & -0.6 & -5.3 & 0.9 & -4.2 & -18.2 & -6 & -13.6 & -5.6 & -13.9 & -13.5 & -3 & -9.1 & -2.4 & -5.7 & -4.02 & -11.46 & -6.74 \\
\hline 25 & -8 & -1.9 & -5 & -4.9 & 4 & -15 & -4 & -9 & -6.5 & -4.2 & \begin{tabular}{|l|}
-9.4 \\
\end{tabular} & -3.2 & -7.9 & -5.8 & 0.3 & -3.16 & -7.74 & -5.2 \\
\hline 26 & -7.2 & -1.4 & 2 & 1.3 & 4 & -10 & -5 & -7.2 & -7 & 3.2 & -8.2 & -3.2 & -2.4 & -2.8 & 3.7 & -0.26 & -5.2 & -2.58 \\
\hline 27 & -8.7 & -2 & 3 & 1.3 & 3.2 & -18 & -5 & -2.4 & 0.3 & 1.7 & -13.2 & -4.1 & 1.6 & 0.9 & 2 & -0.64 & -4.68 & -2.56 \\
\hline 28 & -11 & -0.8 & 5.2 & 0.3 & 1.7 & -19 & -3 & 1 & -1.1 & 0.2 & -15.7 & -2.2 & 3.1 & -0.5 & 0.8 & -0.92 & -4.38 & -2.9 \\
\hline 29 & -14.2 & 0.6 & 2.2 & 1 & 0.6 & -22 & -2 & 0 & -1.5 & -3.2 & -19.2 & -0.9 & 1.2 & -0.3 & -1 & -1.96 & -5.74 & -4.04 \\
\hline 30 & & 1.5 & & & & -22 & -1 & & -0.4 & -7.1 & & 0.1 & 5.0 & & -5.5 & & -5.94 & -4.1 \\
\hline 31 & -8.7 & 2 & 4.4 & 1.1 & -5.1 & -20 & 0 & 0.3 & -0.4 & -10.5 & -14.8 & 0.5 & 2.1 & 0.5 & -8.4 & -1.26 & -6.12 & -4.02 \\
\hline
\end{tabular}

Table 2. Maximum, minimum and average temperatures of July for 2014-2018 in the city of St. Petersburg [35, 36].

\begin{tabular}{|c|c|c|c|c|c|c|c|c|c|c|c|c|c|c|c|c|c|c|}
\hline \multirow{2}{*}{$\begin{array}{c}\text { Day } \\
/ \\
\text { year }\end{array}$} & \multicolumn{5}{|c|}{ Maximum temperature, ${ }^{0} \mathrm{C}$} & \multicolumn{5}{|c|}{ Minimum temperature, ${ }^{0} \mathrm{C}$} & \multicolumn{5}{|c|}{ Average temperature, ${ }^{0} \mathrm{C}$} & \multicolumn{3}{|c|}{ Average, ${ }^{0} \mathrm{C}$} \\
\hline & 14 & 15 & 16 & 17 & 18 & 14 & 15 & 16 & 17 & 18 & 14 & 15 & 16 & 17 & 18 & $\mathrm{~T}_{\max }$ & $T_{\min }$ & $\mathrm{T}_{\mathrm{av}}$ \\
\hline 1 & 18 & 21 & 24 & 15.5 & 14.9 & 13 & 12 & 16 & 11.6 & 8.6 & 15.1 & 17.5 & 20.4 & 13.1 & 11.5 & 18.68 & 12.24 & 15.52 \\
\hline 2 & 19 & 21.7 & 28.1 & 1.8 & 14.8 & 2 & 13.6 & 17 & & 10.4 & 5.6 & 16.8 & 2.7 & 7.2 & 1 & & & 16.84 \\
\hline 3 & 20 & 29 & 31.5 & .2 & 19.7 & 1 & 15 & 17 & .3 & 11.4 & 5.5 & 22.7 & 3.7 & 8.3 & 15.8 & 5.08 & 4 & 19.2 \\
\hline 4 & 20 & 27 & 1.3 & 0.9 & 20.7 & 11 & 18 & 12 & .2 & 11.4 & 4.9 & 22.3 & 16.1 & 0.1 & 10.4 & 1.98 & 12 & 17.16 \\
\hline 5 & 21 & 21 & 14 & 17.1 & 21.1 & 8 & 12 & 12 & 12.8 & 12.8 & 16.1 & 17.3 & 12.7 & 14.6 & 16.3 & 18.84 & .52 & 15.4 \\
\hline 6 & 24 & 18.5 & 16 & 14.6 & 20.3 & 8 & 9 & 12 & 10.9 & 14.4 & 17.8 & 13.9 & 13.7 & 13 & 16.5 & 18.68 & 10.86 & 14.98 \\
\hline 7 & 26.5 & 16 & 15 & 16.1 & 21.7 & 13 & 10 & 13 & 9.6 & 15.5 & 21.3 & 12.7 & 13.9 & 12.5 & 17.7 & 19.06 & 2.22 & 15.62 \\
\hline 8 & 27.2 & 20.6 & 16 & 17.6 & 20.3 & 12 & 13.8 & 13 & 9.7 & 15.6 & 21.1 & 17 & 14.7 & 13.4 & 17.6 & 20.34 & 12.82 & 16.76 \\
\hline 9 & 27 & 22 & 19.2 & 18.4 & 18.6 & 1 & 14 & 1. & 11.1 & 13.8 & 20.3 & 18.1 & 15.9 & 15.1 & 16 & 21.04 & 12.78 & 17.1 \\
\hline 10 & 15.7 & 20.2 & 22.1 & 24.5 & 17.1 & 12 & 11 & 13 & 13.4 & 14.2 & 14.5 & 15.6 & 17.6 & 18.5 & 15.4 & 19.92 & 12.72 & 16.32 \\
\hline 11 & 20.2 & 16 & 22.3 & 24.5 & 24.6 & 9 & 12 & 13 & 12.9 & 13.5 & 15.7 & 14 & 17.9 & 20.2 & 19.2 & 21.52 & 12.08 & 17.4 \\
\hline 12 & 24 & 13.9 & 22 & 23 & 27.4 & 10 & 10 & 15 & 15.7 & 17 & 17.4 & 11.6 & 18.3 & 19.1 & 22.5 & 22.06 & 13.54 & 17.78 \\
\hline 13 & 26 & 16 & 23 & 25.3 & 29 & 15 & 6 & 15 & 15 & 15.6 & 19.5 & 12 & 18.2 & 19.3 & 22.7 & 23.86 & 13.32 & 18.34 \\
\hline 14 & 29 & 18 & 22.4 & 19.4 & 27.8 & 18 & 5 & 14 & 14.6 & 16.6 & 22.2 & 12.9 & 18.5 & 16 & 22.6 & 23.32 & 13.64 & 18.44 \\
\hline 15 & 28 & 20.5 & 22 & 8.3 & 30 & 17 & 7 & 15 & 13.3 & 16.4 & 21.7 & 14.8 & 17.8 & 15.7 & 23.6 & 23.76 & 13.74 & 18.72 \\
\hline 16 & 25 & 21.1 & 21 & 9.7 & 30.7 & 16 & 9 & 14 & 11.9 & 17.4 & 20.7 & 16.1 & 18.1 & 15.9 & 24.8 & 23.5 & 13.66 & 19.12 \\
\hline 17 & 23 & 22 & 25 & 20.8 & 30.7 & 15 & 10 & 13 & 13.8 & 20.4 & 19.3 & 15.6 & 19.7 & 16.3 & 26.1 & 24.3 & 14.44 & 19.4 \\
\hline 18 & 26 & 24 & 19.4 & 18.9 & 27.9 & 14 & 10 & 15 & 13.7 & 21.2 & 20.4 & 17.7 & 16.7 & 15.3 & 24.6 & 23.24 & 14.78 & 18.94 \\
\hline 19 & 26.7 & 20 & 22.4 & 18 & 27.2 & 15 & 12 & 14 & 12.9 & 20.2 & 21.9 & 16.1 & 18.8 & 15.2 & 23.7 & 22.86 & 14.82 & 19.14 \\
\hline
\end{tabular}




\begin{tabular}{|c|c|c|c|c|c|c|c|c|c|c|c|c|c|c|c|c|c|c|}
\hline \multirow{2}{*}{$\begin{array}{l}\text { Day } \\
/ \\
\text { year }\end{array}$} & \multicolumn{5}{|c|}{ Maximum temperature, ${ }^{0} \mathrm{C}$} & \multicolumn{5}{|c|}{ Minimum temperature, ${ }^{\circ} \mathrm{C}$} & \multicolumn{5}{|c|}{ Average temperature, ${ }^{0} \mathrm{C}$} & \multicolumn{3}{|c|}{ Average, ${ }^{0} \mathrm{C}$} \\
\hline & 14 & 15 & 16 & 17 & 18 & 14 & 15 & 16 & 17 & 18 & 14 & 15 & 16 & 17 & 18 & $T_{\max }$ & $T_{\min }$ & $\mathrm{T}_{\mathrm{av}}$ \\
\hline 20 & 27.6 & 21 & & & 26.3 & & & & 2.4 & 18.9 & 2.4 & 16 & & 15 & 22.4 & 22.36 & 14.46 & 18.58 \\
\hline 21 & 25 & 21 & & & & & & & & & & & & 16.2 & & 23 & & .22 \\
\hline 22 & 2 & & & & 26. & & & & & & & & & & 23 & 2.36 & & .68 \\
\hline 23 & 27 & & & & 27.1 & & & & & & & & & & & 3.7 & & \\
\hline 24 & 26.7 & & & & & & & & & & 1.4 & & & & 25 & .32 & 58 & .16 \\
\hline 25 & 27 & & & 19. & 27. & & & & & 18. & 1.5 & & & & 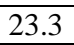 & 4.14 & 4.66 & 9.76 \\
\hline 26 & 30 & & & & & & & & & & & & & & & & & .08 \\
\hline 27 & 3 & & & & 27. & & & & & 20 & 4.6 & & & & 23.8 & 6.34 & .96 & 21.4 \\
\hline 28 & 32 & & & & 29.8 & 1 & & & & 20.8 & 24.8 & 18.1 & & & 25 & 27.56 & .76 & 22.2 \\
\hline 2 & & & & & & & & & & & & & & & & & & 20.4 \\
\hline 30 & 29 & 22 & 20.7 & 21.7 & 27.8 & 16 & 11 & 11 & 15.2 & 18.4 & 23.3 & 15 & 18. & 18.2 & 23.3 & 24.24 & .52 & 19.72 \\
\hline 31 & 33 & 17 & 24 & 23.6 & 28.9 & 19 & 11 & 16 & 15.6 & 18.5 & 25.9 & 14.1 & 19.3 & 19.3 & 23.9 & 25.3 & 16.02 & 20.5 \\
\hline
\end{tabular}

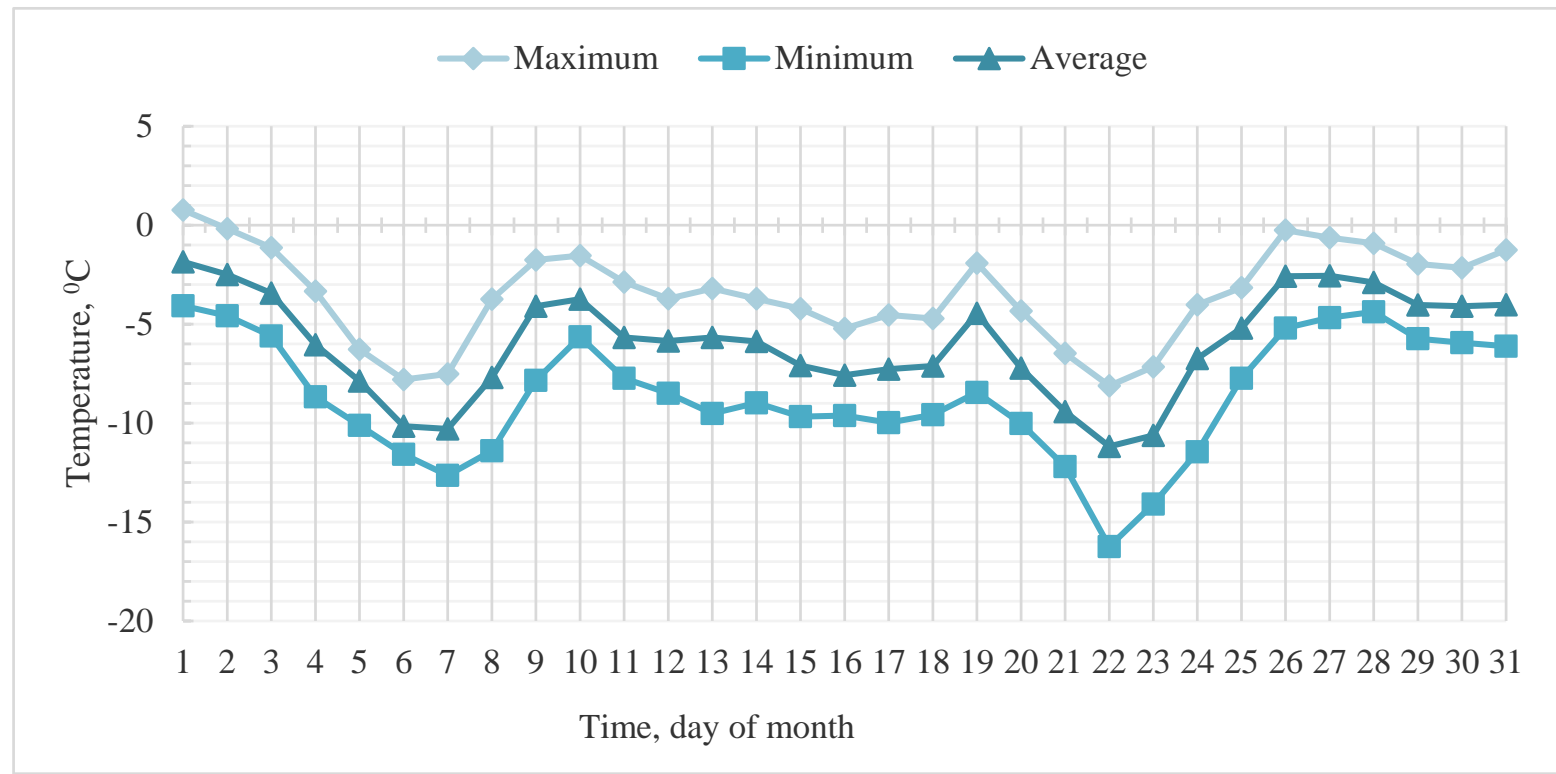

Figure. 1. Graph of averaged maximum, minimum and average temperatures of January for the last five years in the city of St. Petersburg

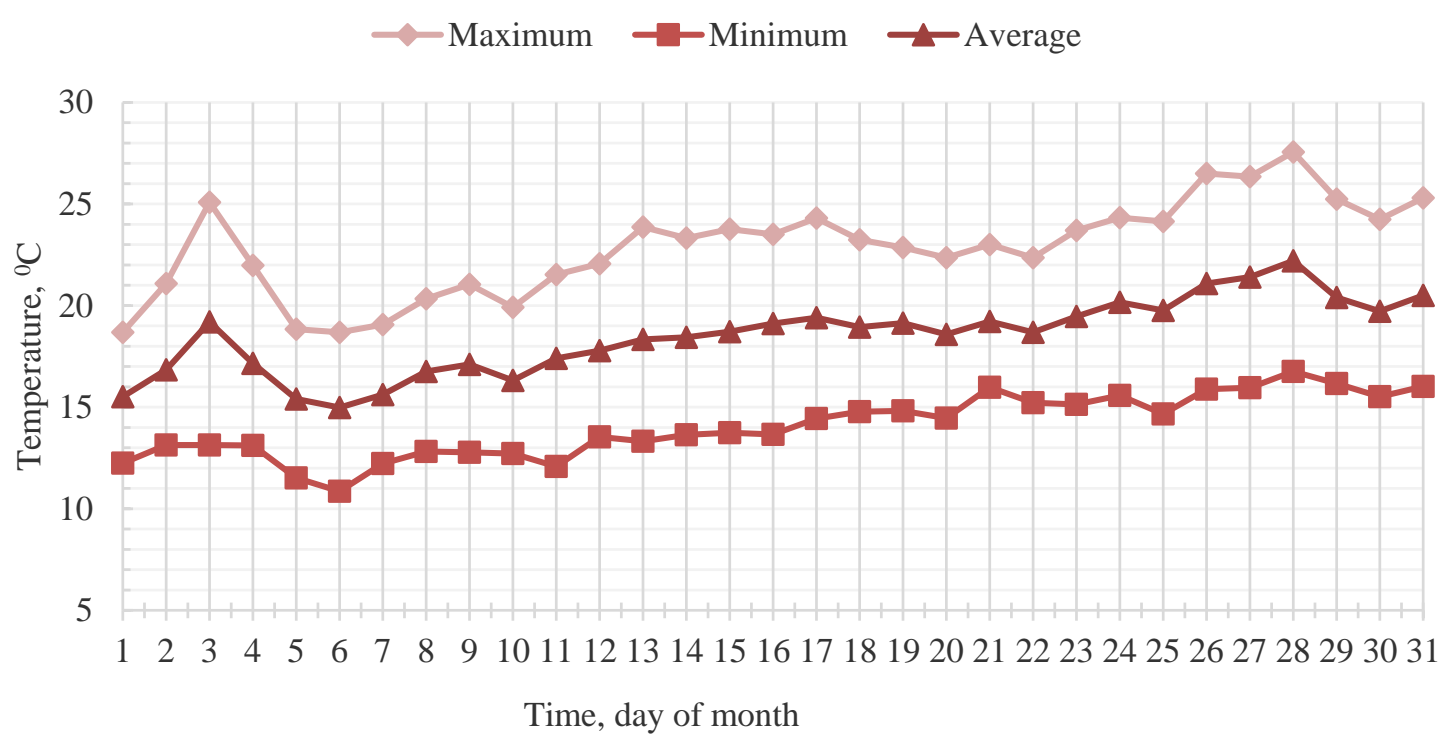

Figure. 2. Graph of averaged maximum, minimum and average temperatures of July for the last five years in the city of St. Petersburg

Let us find the percentage excess between the maximum and minimum temperatures during the day and the average values: 


$$
\frac{T_{\max (\min )}-T_{a V}}{T_{a v}} \cdot 100 \%
$$

Table 3. Comparative table of temperatures

\begin{tabular}{|c|c|c|c|c|}
\hline Month/Factor & $\begin{array}{c}\text { Average difference } \\
\text { between } \mathrm{T}_{\max } \text { and } \mathrm{T}_{\mathrm{av}}\end{array}$ & $\begin{array}{c}\text { Average difference } \\
\text { between } \mathrm{T}_{\max } \text { and } \mathrm{T}_{\mathrm{av}}\end{array}$ & Average value & $\begin{array}{c}\text { Correction Index } \\
\text { for daily average }\end{array}$ \\
\hline July & 23.5 & 24 & 23.75 & 1.24 \\
\hline January & 47.1 & 49.4 & 48.25 & 1.48 \\
\hline
\end{tabular}

Analysis of the results shows the following:

1. Over the past five years, there has been a change in temperature during the month (the difference between the maximum and minimum) within $[6.44 ; 11.94]$ in July and $[3.46 ; 8]$ in December. (Figure. 1, 2);

2. Despite the greatest amplitude of temperature fluctuations in July, as a percentage, the difference between the average temperature and the temperature of the daily maximum / minimum is more significant in January (Table 3).

\subsection{Evaluation of thermal stressed state with constant and variable ambient temperature}

Calculations of this paragraph provide with the same thickness of thermal insulation layer for the case at constant and variable ambient temperature during month. Figure 3 shows graphs of variation in time the thermal stresses in the control points of the base slab height (thickness) $1.0 \mathrm{~m}$ determined at maximum (green line), minimum (red line) and average (blue line) temperatures of January. Figure 4 shows graphs of variation in time temperature difference (center-top) of the base slab height (thickness) $1.0 \mathrm{~m}$ determined at constant (blue line) and variable (red line) ambient temperature of July.

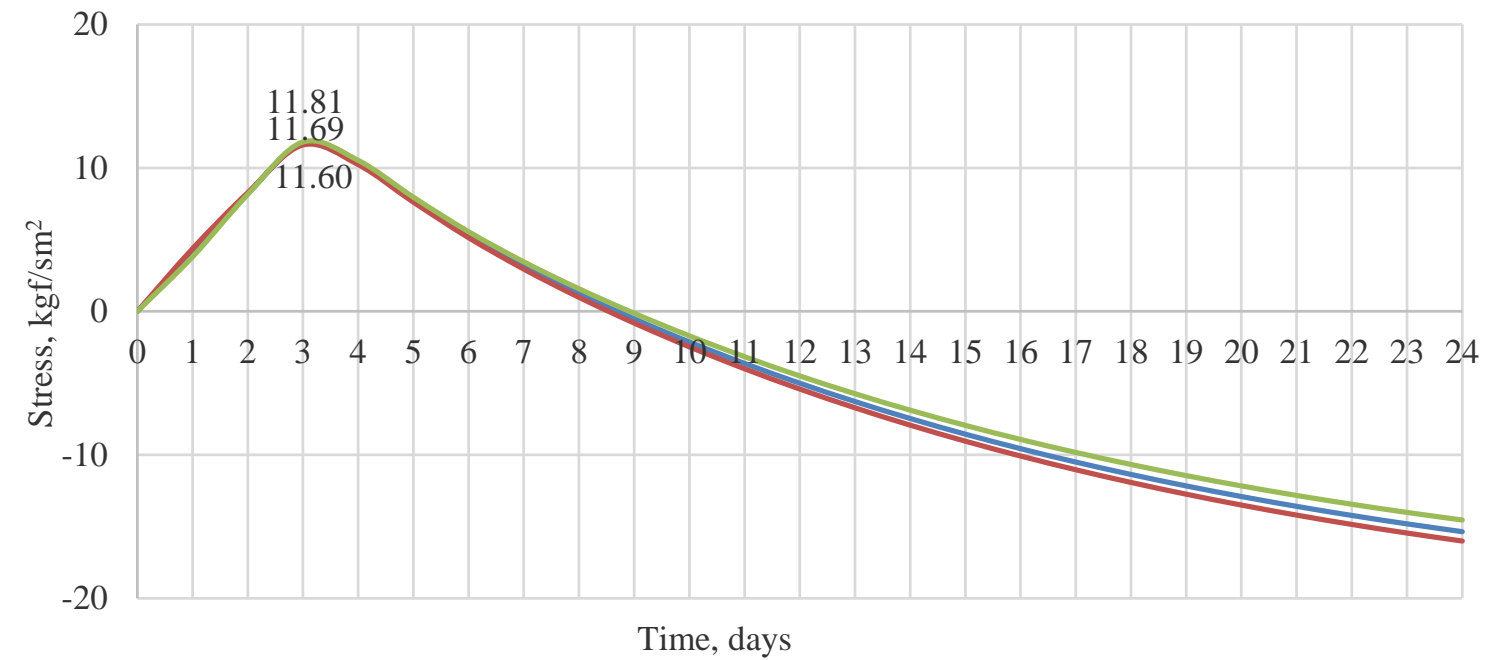

Figure. 3. Graph of changing thermal stresses on the top of the plate determined at maximum, minimum and average temperatures of January in the city of St. Petersburg

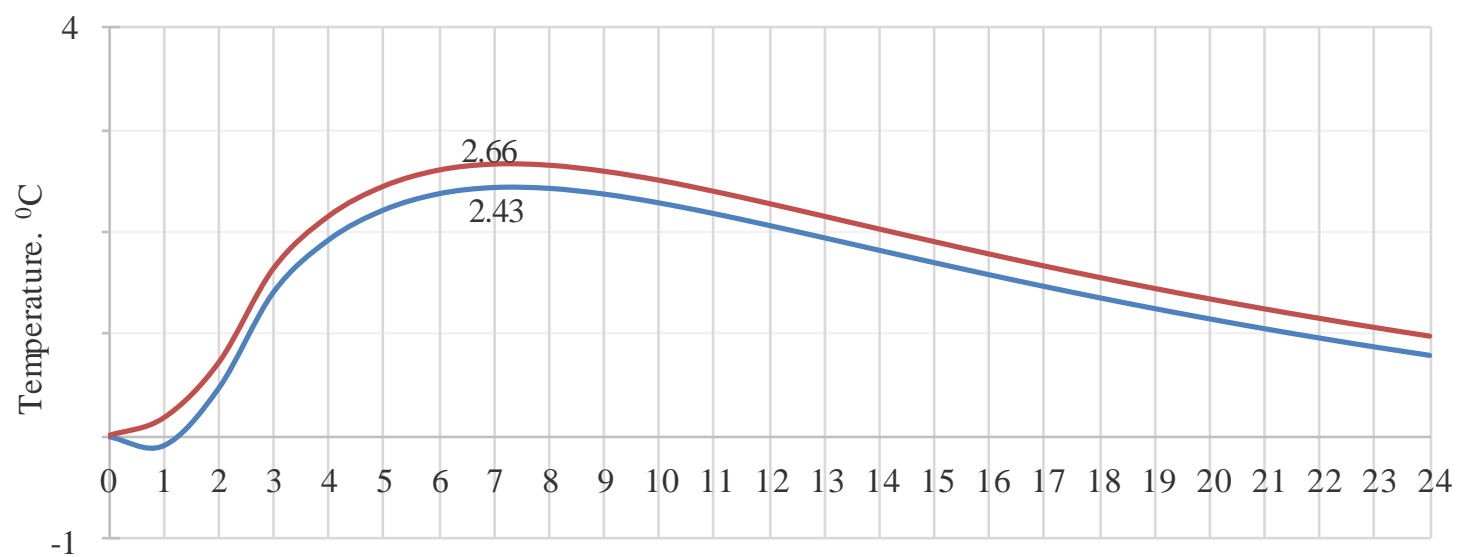

Time, days 
Figure. 4. Graph of changing temperature difference (center-top) of the plate determined at constant and variable ambient temperature of July in the city of St. Petersburg

Analysis of the result show us:

1. The variation of the plate thermal stresses determined at the maximum, minimum and average monthly temperatures is insignificant. The difference is less than 1.5 percent. Furthermore, the maximum and minimum temperatures are local during the month and calculations using the input of the correction factor will be rough enough;

2. Calculations provide for the same thickness of thermal insulation layer for the case at constant and variable ambient temperature show us a negligibly small error in temperatures $(<10 \%)$ and even smaller in thermal stresses $(<0.5 \%)$.

\section{Discussion}

According to the work [3-5, 9-10, 20-22] it is important to have knowledge of aspects having the greatest influence on data calculated while researching the thermal stressed state of massive concrete and reinforced structures. The change in ambient temperature is one of the most significant factors for a large number of processes [24, 26]. For example, according to the paper [27] the deformation conditions occurring in an asphalt base layer because of temperature. In addition, in compliance with [28] the moisture and temperature variations are especially important in porous building materials where water dependent biological and physical processes are the main degrading factors. Calculation with an incorrectly chosen structural model or calculation implying a simplified approach could not be valid qualitative $[1,2,8$, $10,13,14,20-21]$.

According to studies, the solution of the problem of definition the thermal stress state of the massive foundation slab in the building period at constant monthly temperature may not cause a significant distortion of the real diagram of the thermal stresses and elongation deformations in the structures body. For the predicted calculations, it is necessary to derive dependencies describing the daily variations in the ambient air temperature to be included in the calculation method. It is also necessary to analyze the influence of monthly and daily variations in temperature on slabs of various thickness.

\section{Conclusion}

The results of the conducted experiments allow us to make following conclusions:

1. Solving the problem of thermal stressed state of the massive foundation slabs in the building period without taking into account the influence temperature changing during the month may not cause to significant deviation of the real diagram of the thermal stresses and elongation deformations in the structures body: error is less than $0.5 \%$;

2. Despite the minor error at not taking into account the monthly course, daily temperature range should be investigated. The calculation error significant may also depends on the heights of the foundation slab.

\section{References}

1. A. V. Bushmanova, Yu. G. Barabanshchikov, K.V. Semenov, A.Y. Struchkova, S.S. Manovitsky, Mag. of Civ. Eng. 8. $193-200$ (2017)

2. A.V. Bushmanova, D.K. Kharchenko, K.V. Semenov, Yu.G. Barabanshchikov, V. K. Korovina, A.V. Dernakova, Mag. of Civ. Eng. 3. 45-53 (2018)

3. N.A. Malinin, Research of thermal stressed state of mass concrete structures with changing deformations characteristics. Cand. tech. sci. diss. Leningrad, 186. (1977)

4. A.V. Bushmanova, K.V. Semenov, V.K. Korovina, Constr. of Uniq. Build. and Struct. 4 (67). 7-18. (2018)

5. V. Korsun, N. Vatin, A. Franchi, A. Korsun, P. Crespi, S. Mashtaler. Proc. Eng. 117. 970-979 (2015)

6. M.S. Jaafar, et.al. Adv. in Eng. Soft. 38. 886-895 (2007)

7. A. Gorshkov, N. Vatin, D. Nemova, D. Tarasova, Applied Mech. and Mat. 725-726. 3-8 (2015)

8. S. G. Kim, Civil Engineering, Iowa State University, Master of Science Thesis. 126 (2010)

9. I.D. Zaporozhets, S.D. Okorokov, A.A. Pariyskiy, Heat Liberation by concrete. Leningrad-Moscow: Stroyizdat. 316 (1966)

10. A.V. Bushmanova, N.V. Videnkov, K.V. Semenov, Yu.G. Barabanshchikov, A.V. Dernakova, V.K. Korovina, Mag. of Civ. Eng. 3. 51-60 (2017)

11. M.O. Dudin, N.I. Vatin, Yu. G. Barabanshchikov, Mag. of Civ. Eng. 2. 33-45. (2015)

12. K.V. Semenov, Temperature and thermal stressed state of concreting blocks in a high-pressure shell during the building period, L. 156 (1990)

13. V.I. Korsun, A.V. Korsun, Proc. of Mosc. St. Un. of Civ. Eng. 3. 179-188 (2014)

14. Y. Lee, J-K Kim, Comp. and Str. 87. 1085-1101 (2009)

15. Joon-Yuen Won, Sang-Hyun Lee, Tae-Won Park, Kyung-Yong Nam, Const. and Build. Mat. 125. 458-464 (2016)

16. E. Holt, M. Leivo, Cem. and Conc. Comp. 26(5). 521-530 (2004) 
17. M. Larson, Thermal crack estimation in early age concrete-models and methods for practical application. Division of Structural Engineering, Lulea University of Technology, Doctoral Thesis. 190 (2003)

18. J. Se-Jin, ACI Mat. Jour. 105. 325-333 (2008)

19. Z. Zhang, X. Zhang, X. Wang, T. Zhang, App. Mech. and Mat. 94-96. 2107-2110 (2011)

20. A.V. Chekalkin, Thermo-stressed state of concrete foundation of turbine unit of LNPP-2 in construction period. M. Sci. Eng. Tech (2014)

21. E.V. Yamkova, Thermal crack resistance and thermo-stressed state of massive fundamental slab of LNPP-2. M. Sci. Eng. Tech (2015)

22. A.M. Tsybin, Proc. of the VNIIG. 237. 69-76 (2000)

23. S.M. Semenov, E.S. Gelver, Doklady Earth science. 3. 856-850. (2002)

24. M.U. Buzunova, B.F. Kuznetsov, O.A. Dryanov, Reporter IRGSHA. 69. 96-102 (2015)

25. V.N. Razuvaev, E.G. Apasova, O.N. Bulygina, R.A. Martuganov, Atm. Res. 37. 45-51 (1995)

26. S. Eastwood, P. Le Borgne, S. Péré, D. Poulter, Rem. Sens. of Env. 115 is. 10. 2594-2602 (2011)

27. F. Otto, L. Pengfei, Zeyu Zhang, D. Wang, M. Oeser, Inter. J. of Transp. Sc. and Tech. 7 is. 3. $208-216$ (2018)

28. T.K. Thiis, I. Burud, D. Kraniotis, S. Charisia, P. Stefanssona, Proc. Env. Sc. 38. 331-339 (2017)

29. M.A. Zagorul'ko, News of TSU. Tech. science. 3. 33-39 (2012)

30. S.M. Semenov, E.S. Gelver, Russ. Meteor. and Hydr. 11. 17-21 (2002)

31. Russian State standards SP 41.13330.2012. Concrete and reinforced concrete structures of hydroengineering facilities.

32. Russian State standards SP 63.13330.2012. Concrete and reinforced concrete structures.

33. Russian State standards SP 52-101- 2003. Concrete and reinforced concrete structures without prestressing. 34. P.I. Vasil'yev, D.A. Ivanov, Yu.I. Kononov, K.V. Semenov, O.P. Starikov, Probl. of Atom. Science and Tech. 1. 62-68 (1988)

35. Actual weather [online resource]. System requirement: Yandex. URL http://pogoda-service.ru/archive_gsod.php (date of the application: 15.09.2018).

36. Actual weather [online resource]. System requirement: Yandex. URL http://www.pogodaiklimat.ru (date of the application: 15.09.2018). 